\title{
Exosomes as carriers transporting long non-coding RNAs: Molecular characteristics and their function in cancer (Review)
}

\author{
DAMIAN KOŁAT ${ }^{1}$, RANEEM HAMMOUZ ${ }^{2}$, ANDRZEJ K. BEDNAREK ${ }^{2}$ and ELŻBIETA PŁUCIENNIK ${ }^{2}$ \\ ${ }^{1}$ Faculty of Biomedical Sciences and Postgraduate Education; ${ }^{2}$ Department of Molecular Carcinogenesis, \\ Medical University of Łódź, 90-752 Łódź, Poland
}

Received January 15, 2019; Accepted May 9, 2019

DOI: $10.3892 / \mathrm{mmr} .2019 .10340$

\begin{abstract}
Long non-coding RNAs (lncRNAs) comprise a sizeable class of non-coding RNAs with a length of over 200 base pairs. Little is known about their biological function, although over 20,000 lncRNAs have been annotated in the human genome. Through a diverse range of mechanisms, their primary function is in the regulation of the transcription of protein-coding genes. lncRNA transcriptional activation can result from a group of nucleus-retained and chromatin-associated IncRNAs, which function as scaffolds in the cis/trans recruitment of transcription factors, co-activators or chromatin remodelers, and/or promoter enhancers. Exosomes are released as extracellular vesicles and they are produced by endocytic pathways. Their synthesis is initiated by various processes including ceramide synthesis, release of intracellular $\mathrm{Ca}^{2+}$ or acid-base balance disorders. Prior to vesicle creation, selective cargo loading occurs in the Endosomal Sorting Complex Required for Transport. Participation of endosomal sorting proteins such as tetraspanins or specific sumoylated proteins required for transport has been indicated in research. The endosomal-sorting complex consists of four components, these induce the formation of multivesicular bodies and the induction of membrane deformation to form exosomes. Nanovesicles could be formed inside multivesicular bodies to allow transport outside the cell or digestion in lysosomes. The molecular content of exosomes is more heterogenic than its synthesis process, with different cargoes being examined inside vesicles with regard to the type or stage of cancers. This paper will review the importance of lncRNAs as crucial molecular content of exosomes, indicating its involvement in tumour suppression, pro-tumorigenic events and the development of novel therapeutic approaches in the
\end{abstract}

Correspondence to: Dr Elżbieta Płuciennik, Department of Molecular Carcinogenesis, Medical University of Łódź, Zeligowskiego 7/9, 90-752 Łódź, Poland

E-mail: elzbieta.pluciennik@umed.lodz.pl

Key words: exosomes, long non-coding RNA, cancer near future. Further studies of their mechanisms of function are essential, as well as overcoming several challenges to gain a clearer insight to the approaches for the best clinical application.

\section{Contents \\ 1. Introduction \\ 2. Characteristics of exosomes \\ 3. IncRNA \\ 4. Potential usefulness and perspectives}

\section{Introduction}

The term transcriptome encompasses the complete set of RNA molecules applying to an entire organism or specific cell type, making it more dynamic than the genome. It comprises several types of transcripts which are responsible for changes in gene expression. Two major classes of regulatory non-coding RNAs (ncRNAs) which lack any transcriptive capability include microRNAs and long non-coding RNASs (lncRNAs). They play a significant role in diverse cellular processes from enabling normal development to disease progression, as well as cell communication. A valuable example of a biological carrier that can transport abundant quantities of lncRNA is that of the exosome: A type of extracellular vesicle involved in cell-to-cell communication and disease transmission. Its role has been documented in both physiological conditions and pathological changes such as cancer development, where they are responsible for the regulation of various processes including immunosuppression, proliferation and induction of pre-metastatic niche formation. In this review, the role of a number of exosomal lncRNA molecules will be discussed.

\section{Characteristics of exosomes}

The first scientific report to examine the possibility that intracellular structures could be associated with the process of budding vesicles bearing receptors during maturation, using ferritin-labelled proteins and anti-IgG, recorded the 
externalization of transferrin receptors into the intercellular space during sheep reticulocyte maturation (1). The term exosome was later proposed in 1987 (2).

Exosomes are small spherical nanovesicles ranging from 20 to $120 \mathrm{~nm}(3,4)$. They belong to the group of membrane-derived vesicles known as extracellular vesicles (EVs), together with oncosomes, ectosomes or apoptotic bodies (5). The classification of each vesicle to its specific group depends on genesis, composition, size and density (see Table I). Extracellular vesicles can be secreted constitutively or as a result of specific induction (6). The origin of exosomes is linked to the creation of multivesicular bodies (MVBs) in the endosomal pathway; MVBs are structures with a lipid bilayer and a density of 1.12-1.19 g/Ml (7) and which display 5 nucleotidase activity (8).

Exosomes are released from many types of healthy or tumour cells, although more abundantly in the latter (9), and can be found in the tumour microenvironment (TME) and blood samples of cancer patients (10). Physiologically, exosomes can be found in urine (10), sperm (3), amniotic fluid (9) and various other biological fluids. The role of exosomes in metastasis, angiogenesis and epithelial-to-mesenchymal transition (EMT) has been confirmed in cancer development by various studies (9). Exosomes released by tumour cells were shown to constitute a leading source of antigens for dendritic cells inducing antitumour immune responses (11). The physiological functions of exosomes include cellular communication, immunity, infections, elimination of waste products and signalling (12). There is also evidence of their participation in aging-related diseases i.e. neurodegeneration when different types of mRNAs, miRNAs or IncRNA change their abundance inside nanovesicles (13).

Biogenesis. Exosome secretions and their molecular mechanisms are rather obscure, since their release is regulated by several signal molecules and various processes including ceramide synthesis and $\mathrm{Ca}^{2+}$ signalling (3). Proteins that interact with the cell membrane and perform lipid bilayer deformation are epsin, amphiphysin, endofilin, syndapin and dynamin (4). The biogenesis follows the following sequence: The process begins with membrane invagination and exosome release to cytoplasm, followed by early endosome (EE) formation, and then the formation of intraluminal vesicles (ILVs) inside the late endosome (LE).

Under both normal and pathological conditions, exosomes have an endocytic origin and are released by different types of cells. Although exosomes typically mimic the composition of the parent cells, they may contain a few signature proteins. Following the formation of exosomes within the endocytic pathway, they are released from the plasma membrane via MVBs from early endosome maturation and may further fuse with lysosomes or the plasma membrane. The most common and well-known mechanism of cargo sorting is based on the action of proteins from Endosomal Sorting Complex Required for Transport (ESCRT) (6). When this pathway is inactivated, there is a possibility to recruit sumoylated protein hnRNPA2B1 [it binds microRNA (14)] or maintain the signal through tetraspanin-enriched microdomains (TEMs) composed of transmembrane glycoproteins $(8,15)$. The schematic of ESCRT complex based on yeast, is shown in Fig. 1.
The most important proteins associated with ESCRT are: ALIX (ALG-2-interacting protein X), syndecan and syntenin (16). Syntenin ends the formation process through syndecan sorting and binding to ALIX, which affects ESCRT-III (4). Direct ALIX-syntenin interaction is possible through LYPX(n)L motifs (16), which are observed in the viral proteins found in late assembly domains (L-domains), these being responsible for recruiting the host ESCRT machinery directly or via ESCRT-associated proteins. The final product of this ESCRT and auxiliary protein activity is the creation of an MVB containing exosomes.

Despite general syntenin-syndecan-ALIX axis, there are some other molecularindividuals involved in controlling ESCRT. Examples are ADP-ribosylation factor 6 (ARF6) GTPase and Phospholipase D2 (PLD2) enzyme which are considered as proteins associated with syntenin (17) and are responsible for the control of the budding of ILVs into MVBs (18). LIP5 (LYST-interacting protein 5), also known as vesicle trafficking 1 protein (VTA1), is a cofactor for Vps4 ATPase that enhances Vps4-mediated disassembly of ESCRT-III polymer (19). Cep55 (centrosomal protein 55) can mediate ALIX and ESCRT-I complex recruitment; however, interactions with the components of ESCRT-II and ESCRT-III have also been observed (20). Further examples consist of CD2AP (CD2-associated protein), IQGAP1 (IQ-motif-containing GTPase-activating protein 1) or ROCK1 (Rho-associated kinase 1) which are thought to interact with ALIX or TSG-101 (Tumor susceptibility gene 101). They participate in processes such as cytokinesis (20), viral budding (21) and cell polarity (22), respectively. Finally, enzyme heparanase, able to internally cleave heparan sulfate chains on syndecans, acts by increasing exosome production by stimulating intraluminal budding of syndecan and syntenin (23).

After the 'mature' multivesicular body is formed, it can be transported to lysosomes (degraded hydrolytic enzymes) or interact with the lipid membrane, resulting in exosome release outside the cell. In the latter case, the attachment of MVB to the lipid bilayer takes place with the help of Rab-GTP and SNARE family proteins. Examples of these groups are given in Table II.

Following the fusion of MVB and cell membrane, the exosomes can be transported to distant areas of the organism (via blood vessels) or interact with neighbouring cells (4). 'Targeted' cells can internalize nanovesicles in endocytic way where the absorption itself is facilitated through phagocytosis, fusion with cell membrane or ligand-receptor interaction. Fig. 2 presents the process of biogenesis, secretion and absorption of exosomes by means of ESCRT machinery.

Molecular content. Nanovesicle formation exhibits some characteristic stages of biogenesis and involves specific structures present in the cell. The selective mechanism of transporting cargo to the exosome interior is a more heterogenous process, as evidenced by their varied content, even in different types and stages of cancer development (8). The composition of exosomes contains countless types of proteins, including cytokines and growth factors, lipids or nucleic acids (3), including characteristic biomarkers such as CD63, CD81, CD9, TSG-101, ALIX or HSP70 which allow direct identification of exosomes (6).

Proteins. The profile of the proteins within the vesicles consists of cytoplasmic proteins, cell membrane proteins or 
Table I. Subdivision of extracellular vesicles based on their physiological features [based on $(5,14,75)]$.

\begin{tabular}{lccc}
\hline Extracellular vesicles & Size & Density & Origin of vesicles \\
\hline Exosomes & $20-120 \mathrm{~nm}$ & $1.12-1.19 \mathrm{~g} / \mathrm{ml}$ & Multivesicular body \\
Ectosomes & $\sim 0.1-1 \mu \mathrm{m}$ & $\sim 1.16 \mathrm{~g} / \mathrm{ml}$ & Cell membrane \\
Apoptotic bodies & $0.05-5 \mu \mathrm{m}$ & $1.24-1.28 \mathrm{~g} / \mathrm{ml}$ & Cell membrane \\
Oncosomes & $1-10 \mu \mathrm{m}$ & Not specified & Cell membrane \\
\hline
\end{tabular}

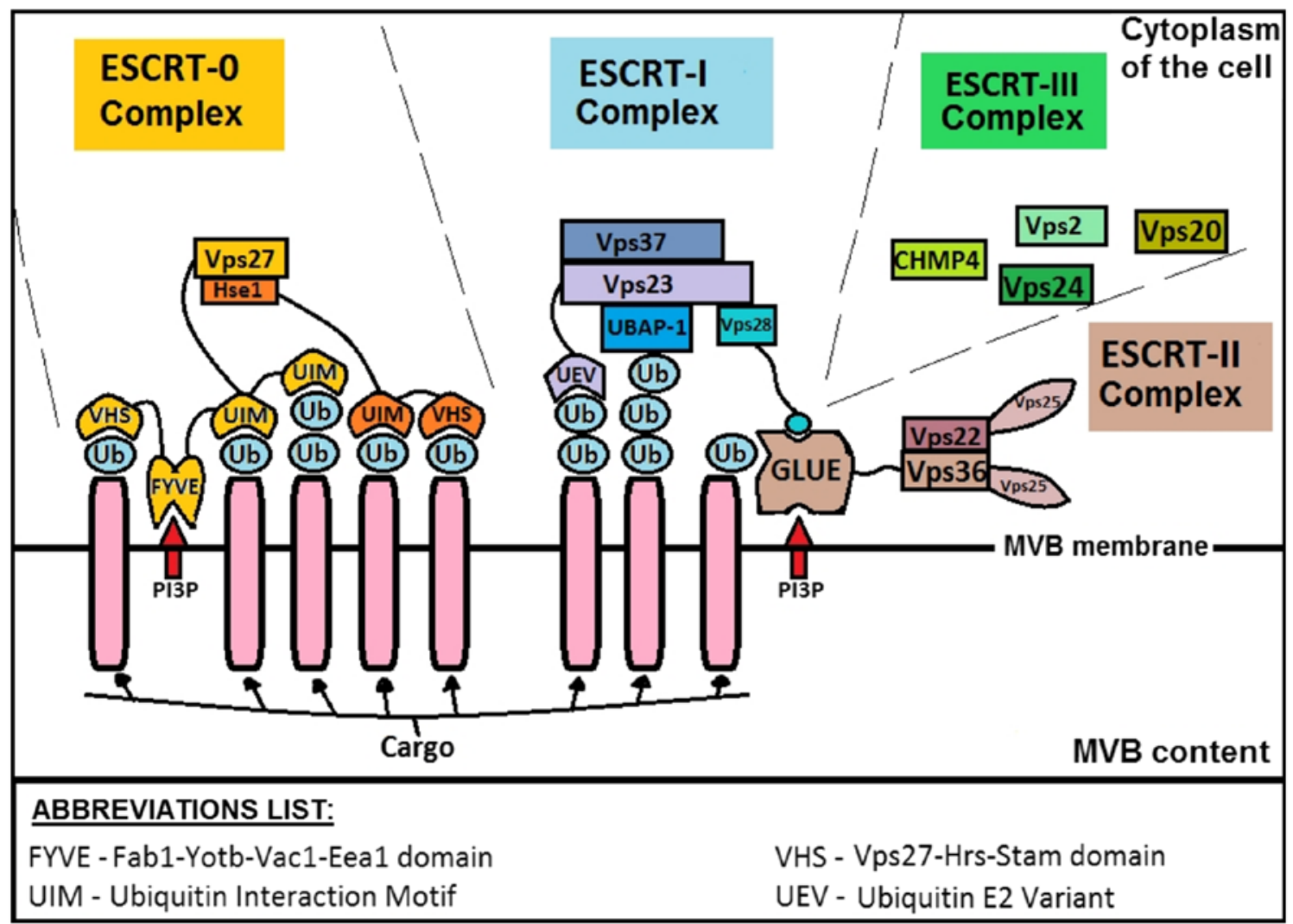

Figure 1. ESCRT formation and cargo sorting of multivesicular body [based on (85)].

proteins from endosomes; however, no proteins from organelles have been detected (6). These proteins include a number of exosomal molecules, such as those connected with MVB biogenesis (e.g., ALIX, TSG-101) (6), ESCRT components (3), transport and fusion proteins (annexin, Rab-GTP, flotillin) and heat shock cognate (HSC). Other important ones include integrins, tetraspanins or subunits of $\mathrm{G}$ proteins. The tumour exosomes (TEXs) include additional molecules that participate in the EMT process including matrix metalloproteinases (MMPs), IL-6, TGF- $\beta$ and immunosupression factors (FasL, TRAIL and GAL-9 that stimulates T cell apoptosis) (8). Some of them are presented in Table III.

Lipids. The lipid composition of exosomes is distinct from that of the cell membrane: it is rich in components such as cholesterol, sphingomyelin, glycerophospholipids, phosphatydylinositol, ceramide or phosphatidilserine, as well as prostaglandins and leukotrienes (6). The lipid content in exosomes is higher than that of the parent cell except phosphatidylcholine which is ordinarily decreased (24). An example of exosomal lipid activity is the differentiation of bone-marrow myeloid cells into myeloid-derived suppressor cells (MDSCs) by prostaglandin E2. The accumulation of MDSCs leads to immunosuppression, which provides favourable conditions for metastasis (8). The participation of lipids in the biogenesis of exosomes is summarized below (Table IV).

Nucleic acids. Exosomes also can include different types of RNA or DNA such as mRNA, miRNA (6), lncRNA, dsDNA, RNA-ROR (regulator of reprogramming) (3), and therefore play a vital role in regulating signaling pathways and gene expression (refer to Table V). These DNA and RNA molecules may be transferred into recipient cell by the fusion of exosome and cell membranes, aiding the regulation of large numbers of signaling pathways or expression of genes (3). Many studies indicate elevated levels of lncRNA in extracellular exosomes compared to parent cells $(25,26)$. This can be attributed to the action of nucleotide patterns that are present in transcripts 
Table II. Selected proteins involved in fusion of MVB with cell membrane and in exosome secretion $[$ based on $(3,4,7,87)]$.

$\begin{array}{lll}\text { Protein } & \text { Proteins family } & \text { Function }\end{array}$

\begin{tabular}{lll}
\hline Rab7; Rab11 & RabGTP & $\begin{array}{l}\text { Promotes proper protein attachment in pathways dependent on calcium ions } \\
\text { Rab27 }(\mathrm{a}, \mathrm{b})\end{array}$ \\
Rab35 & RabGTP & $\begin{array}{l}\text { Regulates the stages of exosome secretion, controls the location of MVB } \\
\text { Regulates exosomes secretion by interacting with GTP-activating protein- } \\
\text { TBC1(Tre- } 2 / B u b 2 / C d c 16)\end{array}$ \\
RAL-1 & RasGTP & $\begin{array}{l}\text { Recruiting the Syx-5 protein, thereby mediating in fusion of membranes } \\
\text { Syx-5 (Syntaxin5) }\end{array}$ \\
VAMP7 & SNARE & Stimulates fusion of MVB with cell membrane \\
SNARE & Necessary for MVB fusion with cell membrane
\end{tabular}

(Vesicle-Associated

Membrane Protein)

YKT6 SNARE Mediates the release of exosomes from the cell

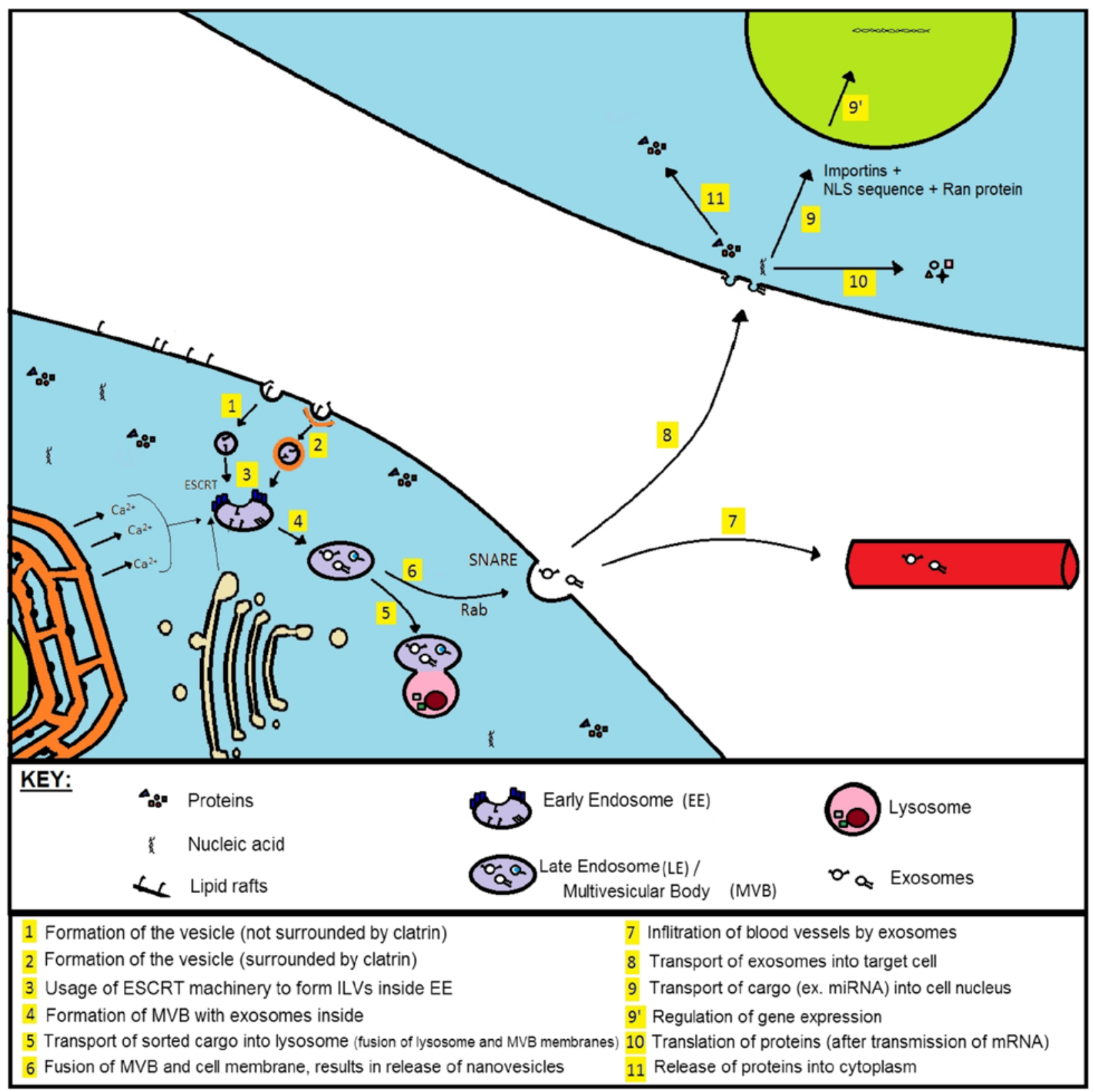

Figure 2. Biogenesis and destination of exosomes inside and outside the cell [based on $(4,5,7,8,86)]$. Nanovesicles in the multivesicular body can be transferred to lysosomes or be released from the cell to enter into blood vessels or fuse with neighboring cells. When entering the target cells, the exosome cargo can exert a different biological effect, resulting in changes in cell physiology for example-reprogramming it into a cancer cell. 
Table III. Examples of exosomal molecules involved in tumour progression, immunosuppression and apoptosis [based on $(3,4,6,10,88,89)]$.

Type of molecule in exosome

Function

Type of cells

ITG $\alpha 6 \beta 4 ;$ ITG $\alpha 6 \beta 1$

ITG $\alpha$ V $\beta 5$

TGF- $\beta$; IL-10; MCP-1 (Monocyte

Chemoattractant Protein-1)

MHC-II (Major Histocompatibility

Complex-II)

OVA (Ovalbumin)

EGFR (Epidermal Growth

Factor Receptor);

KRAS (Kirsten RAt Sarcoma

viral oncogene homolog)

EGFR vIII (EGFR variant III)

MDR-1 (Multi-Drug Resistance)

HER2 (Human Epidermal growth

factor Receptor 2)
Connected with metastasis to the lungs, promotes

TEXs adhesion in the lungs

Connected with metastasis to the liver, binding

to Kupffer cells

Promote cell migration

Stimulation of $\mathrm{CD} 4^{+}$cells

Inhibition of immune response

Proliferation, resistance to treatment

Anti-apoptotic abilities

Resistance for drug

Resistance to treatment with Trastuzumab
Lung cancer cells

Liver cancer cells

Lung cancer cells, melanoma cells

B lymphocytes, DC cells

Melanoma cells

Lung cancer cells

Glioma cells

Prostate cancer cells

Breast cancer cells

Table IV. The examples of lipids involved in formation and secretion of exosomes [based on (9)].

Lipid

Function

Phosphatidylserine

LysoBisPhosphAtidic (LBPA)

BisMonoacylglycerolPhosphate (BMP)

Ceramide

Cholesterol

Lipid rafts (cholesterol-rich

sphingolipid microdomains)

Phosphatidylcholine transporter ABCA3
Participation in microautophagy connected with HSC70 protein (process of exosomes synthesis)

Change in membrane dynamics (in collaboration with ALIX)

Binding to ALIX protein; (BMP formed by PhosphoLipase D2) Involved in the biosynthesis of exosomes and packaging miRNA into them (in a process independent of the ESCRT machinery)

Participation in secretion of FLOT2-positive exosomes

Participation in the biogenesis of exosomes inside MSCs

(Mesenchymal Stem Cells)

Participation in the biogenesis of exosomes derived from B-cell lymphoma as cis-acting elements responsible for targeting them into exosomes (27).

The purpose of this review is to highlight the significance of IncRNA as a pivotal molecule inside exosomes. Therefore, it will summarize the role of various exosomal lncRNAs, together with their function in carcinogenesis and in other biological processes.

\section{IncRNA}

The functional annotation of 60,770 full length longer cDNAs and rare transcripts in the mouse transcriptome resulted in the discovery of a novel class of non-coding cDNAs, among which $\sim 80 \%$ of the transcripts are not spliced (28). The IncRNAs constitute a class of transcripts that does not encode proteins and whose length exceeds $200 \mathrm{bp}$ (29). This group includes several heterogenous molecules that are difficult to categorize: LncRNAs can be divided into long intergenic non-coding RNAs (lincRNAs), long intronic non-coding RNAs and half-STAU1-binding site RNAs (1/2sbsRNAs) (30). Depending on the DNA coding strand, the IncRNAs can be classified as sense or antisense transcripts (31).

Some resemblance can be found between mRNAs and IncRNAs in some biochemical processes, for example mechanisms of polyadenylation and splicing or participation of RNA polymerase II in the process of their transcription (32). The roles of these molecules are connected with transduction signal, decoys, guides or scaffolds (31); however, their main function is associated with their action as transcription regulators of protein-coding genes (32). There is also the probability 
that lncRNAs act like a 'sponge'-leading to miRNA recruitment into EVs, or possibly to provide the mechanisms required for microRNA loading (13).

These findings confirm both the diversity of IncRNAs and their participation in carcinogenesis by demonstrating their influence on the promotion of angiogenesis, protein stability or miRNA inhibition by acting as a sponge. In addition, as IncRNAs are detected in TEXs or apoptotic bodies, and have high stability during circulation, they could be considered as potential cancer biomarkers (33); however, some studies indicate they may display tumour suppression behavior through the blocking of the transcription of apoptosis-inhibiting genes and stimulation of p53 expression (34) or the structural modification of chromatin (35).

lncRNAs as protumorigenic molecules. Numerous studies implicate lncRNAs as cancer-associated molecules that are enriched in exosomes. A classic feature of the tumour microenvironment is hypoxia, which has a notable impact on cancer progression. Activation of its pathway via the transcription factor hypoxia inducible factor (HIF) plays a part in metastasis and a more aggressive phenotype. The role of IncRNAs in hypoxia-driven cancer progression came into view recently, where these hypoxia-responsive IncRNAs play a critical part in regulating hypoxic gene expressions (36). The next subsections will present the characteristics of the most frequent types.

HOTAIR: HOX Transcript Antisense RNA has been associated with progression and poor prognosis in patients with squamous cell carcinoma (SCC), hepatocellular carcinoma (HCC), urothelial bladder cancer (UBC) or colorectal cancer (CRC) (37). Yan et al (38) report the involvement of HOTAIR in the repression of WIF-1-a protein implicated in the Wnt signaling pathway. Moreover, epigenetic regulation is also achievable: It participates in the migration, invasion or proliferation, potentiating through silencing of miR-205 in bladder cancer. In addition, UBC cells displayed increased invasion with migration corresponding to regulation of the EMT pathway, which was confirmed by knockdown of HOTAIR. This resulted in reduced invasiveness by influencing genes connected with EMT such as MMPI (Matrix metalloproteinase-1), ZEB1 (Zinc finger E-box-binding homeobox 1), TWISTI (Twist-related protein 1), SNAI1 (Snail family zinc finger 1), ZO-1 (Zonula occludens 1), LAMC2 (Laminin, gamma 2), $L A M B 3$ (Laminin, beta 3) or $A B L 2$ (ABL proto-oncogene 2) (37). Studies by Xie et al, have shown that salivary HOTAIR could be used as biomarker in diagnostics: it had good discriminatory power for differentiating pancreatic cancer from healthy patients and benign pancreatic tumour $(39,40)$. In addition to its contribution in cancerous diseases, HOTAIR has also been described to play a role in rheumatoid arthritis, where its transcript activates MMP-2 and MMP-13 in synoviocytes and osteoclasts. This could promote joint and cartilage matrix cessation advancing joint destruction. Furthermore, HOTAIR-loaded exosomes with enriched lncRNA activate macrophages and influence immune response (41).

MALAT-1: Metastasis-Associated Lung Adenocarcinoma Transcript 1 or Nuclear-Enriched Abundant Transcript 2 (NEAT-2) was the first lncRNA to be associated with metastasis in Non-Small Cell Lung Cancer (NSCLC). This transcript, similar to the HOTAIR lncRNA, is also connected with migration or tumour growth induction. Zhang et al (42), indicated increased expression of transcript compared to healthy controls, and an association with higher TNM stage in patients with cancer. In vitro study knockdown of MALAT-1 in cancer cell lines significantly inhibited cell proliferation and colony formation, although it also induced cell cycle arrest and cell apoptosis due to a decrease in $\mathrm{S}$ phase progression. In addition, cyclin D1 and cyclin D2 downregulation was also observed, suggesting that MALAT-1 was involved in acceleration of the cell cycle. This indicates that MALAT- 1 can be an important therapeutic target when developing treatments for NSCLC patients, because of its participation in the malignant phenotype of cancer through gene expression regulation (43). Alongside NSCLC, MALAT-1 has been proposed as a mediator of angiogenesis in Thyroid Cancer. Huang et al (44), found it to play a role in the secretion of the fibroblast growth factor 2 (FGF) protein from tumour-associated macrophages (TAMs), which led to vascularization, promotion of proliferation, invasion and migration of cancer cells. Nonetheless, MALAT-1 participation in releasing inflammatory cytokines or FGF2 secretion was predominantly blocked by overexpression of FGF2.

ZFAS1: Initial studies concerning the Zinc Finger AntiSense 1 (ZFAS1) lncRNA refer to alveolar development in the mammary gland, with a proposed role in the regulation of alveolar development and epithelial cell differentiation in the mammary gland (45). The transcript has been found to promote cancer progression by cell cycle regulation through cyclin-dependent kinase 1 (CDK1) interaction or destabilization of the p53 protein. The level of ZFAS1 was also upregulated in exosomes from HCC, CRC and gastric cancer (GC). Pan et al (46), noticed that overexpression of this transcript leads to proliferation and migration of GC cells and ZFAS1-positive exosomes which can be internalized by MKN-28 cells. Knockdown of ZFAS1 inhibited the migration, proliferation and EMT process; however, it also induced cell cycle arrest and programmed cell death, serving as a potential tumour suppressor. These findings have been attributed to decreased ERK, Bcl-2 and increased Bax protein levels. Additionally, ZFAS1 knockdown was observed to suppress cell migration by decreasing the expression of EMT transcription factors such as Slug or Twist. These findings suggest that ZFAS1 could promote metastasis by cell cycle acceleration or support EMT playing a pivotal role in GC diagnosis (47).

H19: H19 lncRNA is also involved in tumor metastasis and has been described as a master factor in cancer biology due to its frequent deregulation in almost all tumours, both in the initiation and progression steps (48). H19 is connected with the downregulation of E-Cadherin, which influences cell adhesion and leads to spread of cancer cells. In addition, Conigliaro et al (49) investigated H19 as a pro-angiogenic molecule promoting cell-to-cell adhesion (CD90+ cells with endothelial cell monolayer) and association with increased expression of VEGF and ICAM1 transcripts which in turn leads to new vessel development. H19 may also act as an epigenetic modulator or as miRNA sponge (50). In conclusion, this type of lncRNA could have a range of impacts on target cells and some of its functions still remain unknown; 
Table V. The examples of nucleic acids that occur in exosomes [based on $(3,6,90)]$.

\begin{tabular}{|c|c|c|}
\hline Nucleic acid & Length in base pairs (bp) & Function \\
\hline mRNA & $\begin{array}{l}\sim 3,250 \text { bp (for TMPRSS } 2 \text { in prostate cancer, } \\
\text { TransMembrane PRotease Serine } 2 \text { ) }\end{array}$ & $\begin{array}{l}\text { Participation in metastasis, progression of } \\
\text { cancer }\end{array}$ \\
\hline $\operatorname{lncRNA}$ & More than $200 \mathrm{bp}$ & $\begin{array}{l}\text { Regulation of gene expression at transcriptional, } \\
\text { posttranscriptional and epigenetic levels }\end{array}$ \\
\hline dsDNA & More than 2,500 bp & $\begin{array}{l}\text { Participation in neoplasm (more frequent occur- } \\
\text { rences in tumour exosomes than exosomes from } \\
\text { normal cells) }\end{array}$ \\
\hline RNA-ROR & $\sim 2,600 \mathrm{bp}$ & $\begin{array}{l}\text { Resistance to chemotherapy in HepatoCellular } \\
\text { Carcinoma, promoting cancerogenesis through } \\
\text { specific histone methylation }\end{array}$ \\
\hline
\end{tabular}

nevertheless, $\mathrm{H} 19$ has been proposed as a potential therapeutic target (e.g., in HCC) (51).

POU3F3: In vitro studies indicate that this transcript increases viability and cell proliferation in gliomas and its overexpression is associated with tumour grading (52). Hu et al (53) investigated whether exosomal POU3F3 from glioma cells could promote angiogenesis and its effect on endothelial cells. They indicate that lncRNA enriched the exosomes regulating the migration, proliferation and angiogenesis of Human Brain Microvascular Endothelial Cells (HBMECs) in both in vitro and in vivo studies. Silencing POU3F3 using shRNA decreased the migratory ability of endothelial cells but did not affect their motility. POU3F3 overexpression in HBMECs caused by lncRNA enriched exosome internalization, and significantly upregulated the transcript level of bFGF, bFGFR, Angio and VEGFA. These findings indicate that POU3F3 lncRNA can be an essential molecule in cell-to-cell communication or a regulator of angiogenesis in glioma cells (53).

TUC339: One of IncRNA transcribed from ultraconserved elements (UCEs) is TUC339. UCEs are 100\% maintained genomic sequences that are greater than 200 bases in length and are conserved across human, mouse and rat genomes (54). The localization of these elements is connected with fragile sites and cancer-associated regions of the genome. Overexpression of this type of IncRNA has been reported in HCC (55). A study on the role of exosomal ultraconserved lncRNA in modulating target cell phenotype as a result of genomic changes found that TUC339 upregulation in HCC cell lines resulted in an enhancement of cell growth and a reduction of adhesion to cell-extracellular matrix (ECM). The knockdown of TUC339 decreased proliferation and altered the expression of a total of 843 genes, 469 of which were inhibited (56).

ROR: LncRNA ROR participates in liver cancer through disruption in TGF- $\beta$ pathway. Although TGF- $\beta$ has been related to cancer chemoresistance, the molecular actions involved in this event remain unknown. Takahashi et al (57), identified a possibly mechanism by which lncRNA may mediate chemoresistance dependent on TGF- $\beta$. They indicate that TGF- $\beta$ reduced the sensitivity of HCC cells to sorafenib or doxorubicin, with a further reduction of sorafenib-dependent caspase $3 / 7$ activity, leading to inhibition of the apoptosis process. Moreover, the release of extracellular vesicles and packaging of IncRNA within vesicles were also modulated by TGF- $\beta$. One of the selectively enriched exosomal lncRNAs thought to be a potential mediator of chemoresistance is RNA-ROR. Using a molecular pathway connected with p53 dependent signaling, lincRNA can contribute to tumor development by inhibiting apoptosis through the repression of p53. Additionally, knockdown of this lncRNA results in increased expression of Caspase 8 and GADD45B, leading to apoptosis induction and growth arrest. These data suggest that lincRNA ROR can be an important mediator in cell-to-cell communication and its contribution in chemoresistance has been confirmed in research. Inhibition of this transcript resulted in reversion of drug resistance, leading to cell death (58).

$V L D L R$ : One of the long-intergenic non-coding RNA transcripts that support HCC development is called VLDLR (59). By showing that knockdown of this RNA can result in cell cycle arrest in G1/S phase, Takahashi et al (60), confirmed that it regulates $\mathrm{HCC}$ cell proliferation. Moreover, the quantity of lncRNA was increased in both HCC cells and extracellular vesicles following chemotherapeutic stress caused by sorafenib, doxorubicin and camptothecin, thus enhancing cell viability. Furthermore, the extracellular transfer of VLDLR to adjacent tumour cells could participate in chemoresistance through the modulation of $A B C G 2$ gene expression.

The summary of the other lncRNA molecules that participate in tumour development is presented in Table VI.

Suppressor function of lncRNA. In contrast to the lncRNAs with pro-cancerous properties, there is also another group of transcripts that could support normal cells rather than stimulating their conversion into a neoplastic phenotype (61).

GAS5: Several studies have implied that the Growth Arrest Specific 5 gene molecule has not been connected with cancer progression, as its expression has been observed to be reduced in various cancer types $(62,63)$. Pickard et al $(64)$, noticed that GAS5 participates in apoptosis regulation in prostate cancer cells. They indicated that the high expression of GAS5 level reduces tumour cell survival and hence induces pro-apoptotic activity. On the other hand, when 
Table VI. Functions of chosen lncRNA molecules in numerous tumour types [based on (91-102)].

\begin{tabular}{|c|c|c|c|}
\hline lncRNA & Function & Tumor type & (Refs.) \\
\hline ARSR & $\begin{array}{l}\text { Resistance to sunitinib; overexpression leads } \\
\text { to poor response of renal cancer patients; } \\
\text { promoting c-MET expression }\end{array}$ & Renal cell carcinoma (RCC) & (91) \\
\hline MEG3 & $\begin{array}{l}\text { Cell cycle arrest; decreases apoptosis by } \\
\text { regulation of miR- } 21\end{array}$ & Cervical cancer (CC) & $(92,93)$ \\
\hline RMRP & $\begin{array}{l}\text { Acts as a miR- } 206 \text { sponge and modulate } \\
\text { the cell cycle by regulating the Cyclin D2 } \\
\text { expression }\end{array}$ & Gastric cancer (GC) & (94) \\
\hline NEAT1 & $\begin{array}{l}\text { Promotes cancer progression through } \\
\text { regulating CDK6 mediated by influence } \\
\text { on miR-107 }\end{array}$ & $\begin{array}{l}\text { Laryngeal squamous } \\
\text { Cell cancer (LSCC) }\end{array}$ & (95) \\
\hline UCA1 & $\begin{array}{l}\text { Enhances cell proliferation, migration, } \\
\text { invasion, EMT process }\end{array}$ & Bladder cancer (BC) & (96) \\
\hline HULC & $\begin{array}{l}\text { Induces angiogenesis and modulates } \\
\text { VEGF expression; upregulates sphingosine } \\
\text { kinase } 1 \text { (SPHK1) by miR-107/E2F1 pathway }\end{array}$ & Liver cancer (LC) & $(97,98)$ \\
\hline TUG1 & $\begin{array}{l}\text { Promotes radioresistance and EMT transition; } \\
\text { enhance proliferation and migration }\end{array}$ & $\begin{array}{l}\text { Bladder cancer }(\mathrm{BC}) \\
\text { Pancreatic cancer }(\mathrm{PC})\end{array}$ & $(99,100)$ \\
\hline HOTTIP & $\begin{array}{l}\text { Increases the chemoresistance by } \\
\text { Wnt/ } \beta \text {-catenin pathway activation }\end{array}$ & Osteosarcoma & (101) \\
\hline CCAT2 & $\begin{array}{l}\text { Upregulates VEGFA and TGF } \beta \text {, promotes } \\
\text { angiogenesis, decreases apoptosis by elevated } \\
\text { Bcl-2 expression and inhibition of Bax and } \\
\text { caspase-3 }\end{array}$ & Glioma cancer & (102) \\
\hline
\end{tabular}

Table VII. Participation of lncRNAs in various diseases [based on $(77,103-110)]$.

\begin{tabular}{|c|c|c|c|}
\hline lncRNA & Disease & Function & (Refs.) \\
\hline CRNDE-h & Colorectal cancer (CRC) & Promotes metabolic changes through insulin/IGF signaling & $(103)$ \\
\hline $\mathrm{p} 21$ & Prostate cancer $(\mathrm{PCa})$ & $\begin{array}{l}\text { Alter gene expression by modulating mRNA translation and } \\
\text { suppressing the p53 or Wnt/ } \beta \text {-catenin pathway }\end{array}$ & $(104)$ \\
\hline PCA3 & Prostate cancer $(\mathrm{PCa})$ & $\begin{array}{l}\text { Modulates the survival of cells downstream of androgen } \\
\text { receptor signaling }\end{array}$ & $(105)$ \\
\hline BCAR4 & Breast cancer $(\mathrm{BC})$ & $\begin{array}{l}\text { Convert phenotype into an estrogen-independent, } \\
\text { antiestrogen-resistant; tamoxifen resistance via HER2 signaling }\end{array}$ & $(106)$ \\
\hline ATB & $\begin{array}{l}\text { Hepatocellular } \\
\text { carcinoma }(\mathrm{HCC})\end{array}$ & $\begin{array}{l}\text { Suppresses E-cadherin, leading to progression of epithelial tumor } \\
\text { cells via inducing EMT }\end{array}$ & $(107)$ \\
\hline ANRIL & $\begin{array}{l}\text { Non-small cell lung } \\
\text { carcinoma (NSCLC) }\end{array}$ & $\begin{array}{l}\text { Affects proliferation and apoptosis using suppression of } \\
\text { KLF2 and P21 transcription }\end{array}$ & $(108)$ \\
\hline LINC00152 & Gastric cancer (GCA) & Connects with depth of invasion among gastric cancer patients & $(109)$ \\
\hline RP11-445H22.4 & Breast cancer $(\mathrm{BC})$ & $\begin{array}{l}\text { Its expression levels correlated with estrogen receptor (ER), } \\
\text { progesterone receptor (PR), and menopausal status of the } \\
\text { breast cancer patients; this molecule showed a remarkable } \\
\text { improvement compared with CEA }\end{array}$ & $(110)$ \\
\hline RP11-1382.1 & $\begin{array}{l}\text { Chronic kidney } \\
\text { disease }(\mathrm{CKD})\end{array}$ & Unknown function & (77) \\
\hline
\end{tabular}


GAS5 was downregulated, programmed cell death was diminished but growth arrest was not. In prostate carcinoma GAS5 has been found to bind to the receptor domain and inhibit transcriptional stimulation, leading to increased death of tumour cells (65).

PARTICL: Some studies also confirmed the role of lncRNAs in the methylation process in response to radiation. One of this IncRNA is PARTICL (promoter of MAT2A antisense radiation-induced circulating long non-coding RNA) a trans-acting mediator of DNA, and histone lysine methylation, a clever component for gene silencing (66). The findings indicate that in low dose irradiation, PARTICL can enhance EZH2 (enhancer of zeste homolog 2) expression, which in turn catalyzes the addition of methyl groups to histone $\mathrm{H} 3$ at lysine 27. Moreover, there was also an observed increase in the activity of the DNMT1 enzyme (DNA methyltransferase 1), global methylome enhancement methylome regulation e.g., CpG island methylation of $W W O X$ gene. Finally, speculation about PARTICL as an epigenetic modifying platform targeting chromatin structure modulation through recruitment of PRC2 (Polycomb Repressive Complex 2) has been proposed; this has been proposed to act by the binding of IncRNA to a subunit of PRC2 called SUZ12 (Suppressor of Zeste 12). These data indicate that PARTICL interlinks regulators of epigenetic modifications that may affect the suppression of transcription (67).

CCND1: Another lncRNA found in exosomes (68) and connected with ionizing radiation-dependent transcription (69) is ncRNA CCND1 (cyclin D1). This single strand transcript binds to the TLS (translocated in liposarcoma) modulator, thus recruiting it to CCND1 promoter and inducing negative regulation of gene transcription. In addition, it also blocks the activity of CREB (cAMP response element binding) and p300 proteins.

EXO1-4: The four molecules that occur abundantly in exosomes in cervical cancer were defined as Exo1-4 (70). Those transcripts contain DNase hypersensitive regions as well as RNAPII and CTCF binding sites (71). Exo1-4 is a subset of lncRNAs that modulate cell function through increasing recipient cell viability by binding to various proteins: For example, Exo2 directly interacts with lactate dehydrogenase B (LDHB) while Exo4 reacts with high mobility group protein 17 (HMG-17). This speculates that IncRNA Exol-4 has an impact on processes like cell metabolism or nucleosomal architecture.

lncRNAs as novel class of tumour biomarkers. Because lncRNA has greater tissue specificity than mRNA (72), these molecules may act as specific diagnostic biomarkers (73). When included in extracellular vesicles, circulation of RNA in body fluids is stable and able to resist the activity of ribonucleases (74), which makes them potential cancer prognostic markers (75). The profiles of lncRNA varies depending on tumour types that may be useful for clinical research, and moreover, these molecules could replace biopsies owing to the reduced level of invasiveness (76). Exosomal IncRNA can be nominated as cancer biomarkers but some of them are responsible for the development of other diseases (77). A set of differently expressed lncRNA associated with non-cancerous or cancerous diseases is shown in Table VII.

\section{Potential usefulness and perspectives}

As a result of maintaining full stability of 1ncRNA in extracellular vesicles as mentioned earlier, these transcripts can be taken up by target cells with their full functionality preserved (78). This make EVs effective nanocarriers that are capable of regulating lncRNAs expression in cancer cells (79). An attractive potential tumour therapy that requires further development maintaining high levels of tumour suppressor lncRNAs or destabilizing oncogenic ones (80). $\mathrm{H} 19$ is an example of the use of pro-tumorigenic long non-coding transcripts in the specific targeting of tumour cells. The regulatory sequence of this lncRNA was used in the successful formation of the BC- 819 plasmid. In vivo this construct encodes the tox in Diphtheria Toxin A (DTA) which provided encouraging results in the treatment of bladder or colon cancer, as well as pancreas carcinoma or NSCLC (81). There are also potential approaches to inducing overexpression of lncRNA MEG3 (Maternally Expressed Gene 3) in lung adenocarcinoma in order to increase sensitivity to cisplatin-based chemotherapy (82). Another potential type of IncRNA-based therapy exploits the 'sponge' activity of those transcripts, resulting in lowered miRNA activity in tumours (81).

Looking prospectively, there are still many challenges to be tackled. Even following the identification of numerous lncRNAs connected with various diseases, there is still the need to identify more transcripts and clarify their mechanism of action. Unbiased genetic screening, lncRNA expression patterns and characterization of associated proteins should provide guidance. Moreover, the development of better technologies directed to improve lncRNA-based therapies will effectively expand their usage as therapeutic or diagnostic strategies. Finally, investigation of new tools using the epigenetic functionality of lncRNAs could help in the research and treatment of diseases that depend on epigenetics (83). When it comes to the development of exosomal lncRNA-based therapeutics, a few problems were identified including uncertain functionality in biological pathways, the pharmacokinetics and toxicity of lncRNAs and the precise quantification of EV-bounded non-coding transcripts which need to be addressed accordingly (84).

In conclusion, progressive studies of lncRNA properties can lead to their use as cancer biomarkers with high sensitivity and accuracy, resulting in early-stage detection, and improved performance of existing clinical biomarkers. Long non-coding RNA can either have a suppressive function in terms of cancer development, or promote its progression. A good example of transporters that carry lncRNAs are exosomes, participating in cell-to-cell communication and thereafter affecting physiological and pathological changes. There are still several challenges that needs to be tackled in order to provide efficient EV-based lncRNAs therapeutics for clinical application, but the current state of research offers promise.

\section{Acknowledgements}

Not applicable. 


\section{Funding}

No funding was received.

\section{Availability of data and materials}

Not applicable.

\section{Authors' contributions}

DK drafted the manuscript, designed the figures, and researched the literature. DK and EP designed the article. $\mathrm{EP}, \mathrm{AKB}$ and $\mathrm{RH}$ revised the article. All authors read and approved the final manuscript.

\section{Ethics approval and consent to participate}

Not applicable.

\section{Patient consent for publication}

Not applicable.

\section{Competing interests}

The authors declare that they have no competing interests.

\section{References}

1. Pan BT and Johnstone RM: Fate of the transferrin receptor during maturation of sheep reticulocytes in vitro: Selective externalization of the receptor. Cell 33: 967-978, 1983.

2. Johnstone RM, Adam M, Hammond JR, Orr L and Turbide C: Vesicle formation during reticulocyte maturation. Association of plasma membrane activities with released vesicles (exosomes). J Boil Chem 262: 9412-9420, 1987.

3. Yu S, Cao H, Shen B and Feng J: Tumor-derived exosomes in cancer progression and treatment failure. Oncotarget 6 : 37151-37168, 2015.

4. Isola AL and Chen S: Exosomes: The link between GPCR activation and metastatic potential? Front Genet 7: 56, 2016.

5. Ciardiello C, Cavallini L, Spinelli C, Yang J, Reis-Sobreiro M, de Candia P, Minciacchi VR and Di Vizio D: Focus on extracellular vesicles: New frontiers of cell-to-cell communication in cancer. Int J Mol Sci 17: 175, 2016.

6. Taverna S, Giallombardo M, Gil-Bazo I, Carreca AP, Castiglia M, Chacartegui J, Araujo A, Alessandro R, Pauwels P, Peeters M and Rolfo C: Exosomes isolation and characterization in serum is feasible in non-small cell lung cancer patients: Critical analysis of evidence and potential role in clinical practice. Oncotarget 7 : 28748-28760, 2016.

7. Fu H, Yang H, Zhang $\mathrm{X}$ and $\mathrm{Xu} \mathrm{W}$ : The emerging roles of exosomes in tumor-stroma interaction. J Cancer Res Clin Oncol 142: 1897-1907, 2016.

8. Soung YH, Nguyen T, Cao H, Lee J and Chung J: Emerging roles of exosomes in cancer invasion and metastasis. BMB Rep 49: 18-25, 2016.

9. Rahman MA, Barger JF, Lovat F, Gao M, Otterson GA and Nana-Sinkam P: Lung cancer exosomes as drivers of epithelial mesenchymal transition. Oncotarget 7: 54852-54866, 2016.

10. Wang Y, Yi J, Chen X,Zhang Y, Xu M and Yang Z: The regulation of cancer cell migration by lung cancer cell-derived exosomes through TGF- $\beta$ and IL-10. Oncol Lett 11: 1527-1530, 2016.

11. Bobrie A and Thery C: Unraveling the physiological functions of exosome secretion by tumors. Oncoimmunology 2: e22565, 2013.

12. De Toro J, Herschlik L, Waldner C and Mongini C: Emerging roles of exosomes in normal and pathological conditions: New insights for diagnosis and therapeutic applications. Front Immunol 6: 203, 2015.
13. Kim KM, Abdelmohsen K, Mustapic M, Kapogiannis D and Gorospe M: RNA in extracellular vesicles. Wiley Interdiscip Rev RNA 8: 2017.

14. Neviani P and Fabbri M: Exosomic microRNAs in the tumor microenvironment. Front Med (Lausanne) 2: 47, 2015.

15. Martin F, Roth DM, Jans DA, Pouton CW, Partridge LJ, Monk PN and Moseley GW: Tetraspanins in viral infections: A fundamental role in viral biology? J Virol 79: 10839-10851, 2005.

16. Baietti MF, Zhang Z, Mortier E, Melchior A, Degeest G, Geeraerts A, Ivarsson Y, Depoortere F, Coomans C, Vermeiren E, et al: Syndecan-syntenin-ALIX regulates the biogenesis of exosomes. Nat Cell Biol 14: 677-685, 2012.

17. Fares J, Kashyap R and Zimmermann P: Syntenin: Key player in cancer exosome biogenesis and uptake? Cell Adh Migr 11: 124-126, 2017.

18. Ghossoub R, Lembo F, Rubio A, Gaillard CB, Bouchet J, Vitale N, Slavík J, Machala M and Zimmermann P: Syntenin-ALIX exosome biogenesis and budding into multivesicular bodies are controlled by ARF6 and PLD2. Nat Commun 5: 3477, 2014.

19. Shim S: Role and regulation of ESCRT-III In multivesiculr body biogenesis. All Theses and Dissertations (ETDs). 323, 2009.

20. Roxrud I, Stenmark H and Malerod L: ESCRT \& Co. Biol Cell 102: 293-318, 2010.

21. Votteler J and Sundquist WI: Virus budding and the ESCRT pathway. Cell Host Microbe 14: 232-241, 2013.

22. Amano M, Nakayama M and Kaibuchi K: Rho-kinase/ROCK: A key regulator of the cytoskeleton and cell polarity. Cytoskeleton (Hoboken) 67: 545-554, 2010.

23. Roucourt B, Meeussen S, Bao J, Zimmermann P and David G: Heparanase activates the syndecan-syntenin-ALIX exosome pathway. Cell Res 25: 412-428, 2015.

24. Roma-Rodrigues C, Fernandes AR and Baptista PV: Exosome in tumour microenvironment: Overview of the crosstalk between normal and cancer cells. Biomed Res Int 2014: 179486, 2014.

25. Gezer U, Ozgur E, Cetinkaya M, Isin M and Dalay N: Long non-coding RNAs with low expression levels in cells are enriched in secreted exosomes. Cell Biol Int 38: 1076-1079, 2014.

26. Schageman J, Zeringer E, Li M, Barta T, Lea K, Gu J, Magdaleno S, Setterquist R and Vlassov AV: The complete exosome workflow solution: From isolation to characterization of RNA cargo. Biomed Res Int 2013: 253957, 2013.

27. Batagov AO, Kuznetsov VA and Kurochkin IV: Identification of nucleotide patterns enriched in secreted RNAs as putative cis-acting elements targeting them to exosome nano-vesicles. BMC Genomics 3 (Suppl 12): S18, 2011.

28. Okazaki Y, Furuno M, Kasukawa T, Adachi J, Bono H, Kondo S, Nikaido I, Osato N, Saito R, Suzuki H, et al: Analysis of the mouse transcriptome based on functional annotation of 60,770 full-length cDNAs. Nature 420: 563-573, 2002.

29. Kapranov P, Cheng J, Dike S, Nix DA, Duttagupta R, Willingham AT, Stadler PF, Hertel J, Hackermüller J, Hofacker IL, et al: RNA maps reveal new RNA classes and a possible function for pervasive transcription. Science 316: 1484-1488, 2007.

30. Perkel JM: Visiting 'noncodarnia'. Biotechniques 54: 301 303-304, 2013.

31. Wang KC and Chang HY: Molecular mechanisms of long noncoding RNAs. Mol Cell 43: 904-914, 2011.

32. Sato-Kuwabara Y, Melo SA, Soares FA and Calin GA: The fusion of two worlds: Non-coding RNAs and extracellular vesicles-diagnostic and therapeutic implications (Review). Int J Oncol 46: 17-27, 2015.

33. Bolha L, Ravnik-Glavac M and Glavac D: Long noncoding RNAs as biomarkers in cancer. Dis Markers 2017: 7243968, 2017.

34. Hewson C and Morris K V: Form and function of exosome-associated long non-coding RNAs in cancer. Curr Top Microbiol Immunol 394: 41-56, 2016.

35. Zhao J, Ohsumi TK, Kung JT, Ogawa Y, Grau DJ, Sarma K, Song JJ, Kingston RE, Borowsky M and Lee JT: Genome-wide identification of polycomb-associated RNAs by RIP-seq. Mol Cell 40: 939-953, 2010.

36. Shih JW and Kung HJ: Long non-coding RNA and tumor hypoxia: New players ushered toward an old arena. J Biomed Sci 24: 53, 2017.

37. Berrondo C, Flax J, Kucherov V, Siebert A, Osinski T, Rosenberg A, Fucile C, Richheimer S and Beckham CJ: Expression of the long non-coding RNA HOTAIR correlates with disease progression in bladder cancer and is contained in bladder cancer patient urinary exosomes. PLoS One 11: e0147236, 2016. 
38. Yan TH, Lu SW, Huang YQ, Que GB, Chen JH, Chen YP, et al. Upregulation of the long noncoding RNA HOTAIR predicts recurrence in stage $\mathrm{Ta} / \mathrm{T} 1$ bladder cancer. Tumour biology : the journal of the International Society for Oncodevelopmental Biology and Medicine. 2014;35(10):10249-57.

39. Xie Z, Chen X, Li J, Guo Y, Li H, Pan X, Jiang J, Liu H and Wu B: Salivary HOTAIR and PVT1 as novel biomarkers for early pancreatic cancer. Oncotarget 7: 25408-25419, 2016.

40. Wang J, Zhang X, Ji C, Zhang L, Di Y, Lou W, Zhang X and X $\mathrm{J}$ : Novel implications of exosomes and lncRNAs in the diagnosis and treatment of pancreatic cancer. In: Novel Implications of Exosomes in Diagnosis and Treatment of Cancer and Infectious Diseases. Wang J (ed). IntechOpen, 2017. Available from: https:// www.intechopen.com/books/novel-implications-of-exosomesin-diagnosis-and-treatment-of-cancer-and-infectious-diseases/ novel-implications-of-exosomes-and-lncrnas-in-the-diagnosisand-treatment-of-pancreatic-cancer. [Accessed 09th May 2019].

41. Song J, Kim D, Han J, Kim Y, Lee M and Jin EJ: PBMC and exosome-derived Hotair is a critical regulator and potent marker for rheumatoid arthritis. Clin Exp Med 15: 121-126, 2015.

42. Zhang R, Xia Y, Wang Z, Zheng J, Chen Y, Li X, Wang Y and Ming H: Serum long non coding RNA MALAT-1 protected by exosomes is up-regulated and promotes cell proliferation and migration in non-small cell lung cancer. Biochem Biophys Res Commun 490: 406-414, 2017.

43. Gutschner T, Hammerle M, Eissmann M, Hsu J, Kim Y, Hung G, Revenko A, Arun G, Stentrup M, Gross M, et al: The noncoding RNA MALAT1 is a critical regulator of the metastasis phenotype of lung cancer cells. Cancer Res 73: 1180-1189, 2013.

44. Huang JK, Ma L, Song WH, Lu BY, Huang YB, Dong HM, Ma XK, Zhu ZZ and Zhou R: LncRNA-MALAT1 promotes angiogenesis of thyroid cancer by modulating tumor-associated macrophage FGF2 protein secretion. J Cell Biochem 118 4821-4830, 2017.

45. Askarian-Amiri ME, Crawford J, French JD, Smart CE, Smith MA, Clark MB, Ru K, Mercer TR, Thompson ER, Lakhani SR, et al: SNORD-host RNA Zfas1 is a regulator of mammary development and a potential marker for breast cancer. RNA 17 878-891, 2011.

46. Pan L, Liang W, Fu M, Huang ZH, Li X, Zhang W, Zhang P, Qian $\mathrm{H}$, Jiang PC, Xu WR and Zhang X: Exosomes-mediated transfer of long noncoding RNA ZFAS1 promotes gastric cancer progression. J Cancer Res Clin Oncol 143: 991-1004, 2017.

47. Zhou H, Wang F, Chen H, Tan Q, Qiu S, Chen S, Jing W, Yu M, Liang $\mathrm{C}$, Ye $\mathrm{S}$ and $\mathrm{Tu} \mathrm{J}$ : Increased expression of long-noncoding RNA ZFAS1 is associated with epithelial-mesenchymal transition of gastric cancer. Aging (Albany NY) 8: 2023-2038, 2016.

48. Matouk IJ, Halle D, Raveh E, Gilon M, Sorin V and Hochberg A: The role of the oncofetal H19 lncRNA in tumor metastasis: Orchestrating the EMT-MET decision. Oncotarget 7: 3748-3765, 2016.

49. Conigliaro A, Costa V, Lo Dico A, Saieva L, Buccheri S, Dieli F, Manno M, Raccosta S, Mancone C, Tripodi M, et al: CD90+ liver cancer cells modulate endothelial cell phenotype through the release of exosomes containing H19 lncRNA. Mol Cancer 14: $155,2015$.

50. Kallen AN, Zhou XB, Xu J, Qiao C, Ma J, Yan L, Lu L, Liu C, Y JS, Zhang H, et al: The imprinted H19 IncRNA antagonizes let-7 microRNAs. Mol Cell 52: 101-112, 2013.

51. George $\mathrm{J}$ and Patel T: Noncoding RNA as therapeutic targets for hepatocellular carcinoma. Semin Liver Dis 35: 63-74, 2015

52. Lang HL, Hu GW, Chen Y, Liu Y, Tu W, Lu YM, Wu L and Xu GH: Glioma cells promote angiogenesis through the release of exosomes containing long non-coding RNA POU3F3. Eur Rev Med Pharmacol Sci 21: 959-972, 2017.

53. Hu C, Chen M, Jiang R, Guo Y, Wu M, Zhang X. Exosome-related tumor microenvironment. Journal of Cancer. 2018;9(17):3084 92.

54. Mitra SA, Mitra AP and Triche TJ: A central role for long non-coding RNA in cancer. Front Genet 3: 17, 2012.

55. Braconi C, Valeri N, Kogure T, Gasparini P, Huang N, Nuovo GJ, Terracciano L, Croce CM and Patel T: Expression and functional role of a transcribed noncoding RNA with an ultraconserved element in hepatocellular carcinoma. Proc Natl Acad Sci USA 108: 786-791, 2011.

56. Kogure T, Yan IK, Lin WL and Patel T: Extracellular vesicle-mediated transfer of a novel long noncoding RNA TUC339: A mechanism of intercellular signaling in human hepatocellular cancer. Genes Cancer 4: 261-272, 2013.
57. Takahashi K, Yan IK, Kogure T, Haga H and Patel T: Extracellular vesicle-mediated transfer of long non-coding RNA ROR modulates chemosensitivity in human hepatocellular cancer. FEBS Open Bio 4: 458-467, 2014.

58. Li Y, Jiang B, Zhu H, Qu X, Zhao L, Tan Y, Jiang Y, Liao M and $\mathrm{Wu} \mathrm{X}$ : Inhibition of long non-coding RNA ROR reverses resistance to Tamoxifen by inducing autophagy in breast cancer. Tumour Biol 39: 1010428317705790, 2017.

59. Yang N, Li S, Li G, Zhang S, Tang X, Ni S, Jian X, Xu C, Zhu $\mathrm{J}$ and $\mathrm{Lu} \mathrm{M}$ : The role of extracellular vesicles in mediating progression, metastasis and potential treatment of hepatocellular carcinoma. Oncotarget 8: 3683-3695, 2017.

60. Takahashi K, Yan IK, Wood J, Haga H and Patel T: Involvement of extracellular vesicle long noncoding RNA (linc-VLDLR) in tumor cell responses to chemotherapy. Mol Cancer Res 12: $1377-1387,2014$

61. Fritah S, Niclou SP and Azuaje F: Databases for lncRNAs: A comparative evaluation of emerging tools. RNA 20: 1655-1665, 2014.

62. Mourtada-Maarabouni M, Pickard MR, Hedge VL, Farzaneh F and Williams GT: GAS5, a non-protein-coding RNA, controls apoptosis and is downregulated in breast cancer. Oncogene 28: 195-208, 2009.

63. Lucafò M, Stocco G and Decorti GJTCR: Emerging molecular mechanisms underlying cancer metastasis: The rising role of the long non-coding RNA GAS5. Transl Cancer Res 5 (Suppl 4): S827-S830, 2016.

64. Pickard MR, Mourtada-Maarabouni M and Williams GT: Long non-coding RNA GAS5 regulates apoptosis in prostate cancer cell lines. Biochim Biophys Acta 1832: 1613-1623, 2013.

65. Kino T, Hurt DE, Ichijo T, Nader N and Chrousos GP: Noncoding RNA gas5 is a growth arrest- and starvation-associated repressor of the glucocorticoid receptor. Sci Signal 3: ra8, 2010.

66. O'Leary VB, Hain S, Maugg D, Smida J, Azimzadeh O, Tapio S, Ovsepian SV and Atkinson MJ: Long non-coding RNA PARTICLE bridges histone and DNA methylation. Sci Rep 7: 1790, 2017

67. O'Leary VB, Ovsepian SV, Carrascosa LG, Buske FA, Radulovic V, Niyazi M, Moertl S, Trau M, Atkinson MJ and Anastasov $\mathrm{N}$ : PARTICLE, a triplex-forming long ncrna, regulates locus-specific methylation in response to low-dose irradiation. Cell Rep 11: 474-485, 2015.

68. Deng J, Tang J, Wang G and Zhu YS: Long non-coding RNA as potential biomarker for prostate cancer: Is it making a difference? Int J Environ Res Public Health 14: E270, 2017.

69. Wang X, Arai S, Song X, Reichart D, Du K, Pascual G, Tempst P, Rosenfeld MG, Glass CK and Kurokawa R: Induced ncRNAs allosterically modify RNA-binding proteins in cis to inhibit transcription. Nature 454: 126-130, 2008.

70. Di Liegro CM, Schiera G and Di Liegro I: Extracellular vesicle-associated RNA as a carrier of epigenetic information. Genes (Basel) 8: E240, 2017.

71. Hewson C, Capraro D, Burdach J, Whitaker N and Morris KV: Extracellular vesicle associated long non-coding RNAs functionally enhance cell viability. Noncoding RNA Res 1: 3-11, 2016.

72. Derrien T, Johnson R, Bussotti G, Tanzer A, Djebali S, Tilgner H, Guernec G, Martin D, Merkel A, Knowles DG, et al: The GENCODE v7 catalog of human long noncoding RNAs: Analysis of their gene structure, evolution, and expression. Genome Res 22: 1775-1789, 2012

73. Yarmishyn AA and Kurochkin IV: Long noncoding RNAs: A potential novel class of cancer biomarkers. Front Genet 6: 145, 2015.

74. Shi T, Gao G and Cao Y: Long noncoding RNAs as novel biomarkers have a promising future in cancer diagnostics. Dis Markers 2016: 9085195, 2016.

75. Akers JC, Gonda D, Kim R, Carter BS and Chen CC: Biogenesis of extracellular vesicles (EV): Exosomes, microvesicles, retrovirus-like vesicles, and apoptotic bodies. J Neurooncol 113: 1-11, 2013.

76. Silva A, Bullock M and Calin G: The clinical relevance of long non-coding RNAs in cancer. Cancers (Basel) 7: 2169-2182, 2015.

77. Khurana R, Ranches G, Schafferer S, Lukasser M, Rudnicki M, Mayer $\mathrm{G}$ and Hüttenhofer A: Identification of urinary exosomal noncoding RNAs as novel biomarkers in chronic kidney disease. RNA 23: 142-152, 2017

78. Takahashi K, Yan IK, Haga $\mathrm{H}$ and Patel $\mathrm{T}$ : Modulation of hypoxia-signaling pathways by extracellular linc-RoR. J Cell Sci 127: 1585-1594, 2014. 
79. Gutschner T, Richtig G, Haemmerle M and Pichler M: From biomarkers to therapeutic targets-the promises and perils of long non-coding RNAs in cancer. Cancer Metastasis Rev 37: 83-105, 2018.

80. Rao AKDM, Rajkumar T and Mani S: Perspectives of long non-coding RNAs in cancer. Mol Boil Rep 44: 203-18, 2017.

81. Smaldone MC and Davies BJ: BC-819, a plasmid comprising the $\mathrm{H} 19$ gene regulatory sequences and diphtheria toxin $\mathrm{A}$, for the potential targeted therapy of cancers. Curr Opin Mol Ther 12: 607-616, 2010.

82.Liu J, Wan L, Lu K, Sun M, Pan X, Zhang P, Lu B, Liu G and Wang Z: The long noncoding RNA MEG3 contributes to cisplatin resistance of human lung adenocarcinoma. PLoS One 10: e0114586, 2015

83. Wu R, Su Y, Wu H, Dai Y, Zhao M and Lu Q: Characters, functions and clinical perspectives of long non-coding RNAs. Mol Genet Genomics 291: 1013-1033, 2016.

84. Qi P, Zhou XY and Du X: Circulating long non-coding RNAs in cancer: Current status and future perspectives. Mol Cancer 15: 39, 2016.

85. Schmidt $\mathrm{O}$ and Teis D: The ESCRT machinery. Curr Biol 22: R116-R120, 2012.

86. Keller S, Sanderson MP, Stoeck A and Altevogt P: Exosomes: From biogenesis and secretion to biological function. Immunol Lett 107: 102-108, 2006.

87. Ruiz-Martinez M, Navarro A, Marrades RM, Vinolas N, Santasusagna S, Munoz C, Ramírez J, Molins L and Monzo M YKT6 expression, exosome release, and survival in non-small cell lung cancer. Oncotarget 7: 51515-51524, 2016.

88. Hoshino A, Costa-Silva B, Shen TL, Rodrigues G, Hashimoto A, Tesic Mark M, Molina H, Kohsaka S, Di Giannatale A, Ceder $\mathrm{S}$, et al: Tumour exosome integrins determine organotropic metastasis. Nature 527: 329-335, 2015.

89. Yang $\mathrm{C}$ and Robbins PD: The roles of tumor-derived exosomes in cancer pathogenesis. Clin Dev Immunol 2011: 842849, 2011.

90.Zhang A, Zhou N, Huang J, Liu Q, Fukuda K, Ma D, Lu Z, Bai $\mathrm{C}$, Watabe $\mathrm{K}$ and Mo YY: The human long non-coding RNA-RoR is a p53 repressor in response to DNA damage. Cell Res 23: 340-350, 2013.

91. Qu L, Ding J, Chen C, Wu ZJ, Liu B, Gao Y, Chen W, Liu F, Sun W, Li XF, et al: Exosome-transmitted lncARSR promotes sunitinib resistance in renal cancer by acting as a competing endogenous RNA. Cancer Cell 29: 653-668, 2016.

92.Zhang J, Liu SC, Luo XH, Tao GX, Guan M, Yuan H and Hu DK: Exosomal long noncoding RNAs are differentially expressed in the cervicovaginal lavage samples of cervical cancer patients. J Clin Lab Anal 30: 1116-1121, 2016.

93. Zhang J, Yao T, Wang Y, Yu J, Liu Y and Lin Z: Long noncoding RNA MEG3 is downregulated in cervical cancer and affects cell proliferation and apoptosis by regulating miR-21. Cancer Boil Ther 17: 104-113, 2016.

94. Shao Y, Ye M, Li Q, Sun W, Ye G, Zhang X, Yang Y, Xiao B and Guo J: LncRNA-RMRP promotes carcinogenesis by acting as a miR-206 sponge and is used as a novel biomarker for gastric cancer. Oncotarget 7: 37812-37824, 2016

95. Wang P, Wu T, Zhou H, Jin Q, He G, Yu H, Xuan L, Wang X, Tian L, Sun Y, et al: Long noncoding RNA NEAT1 promotes laryngeal squamous cell cancer through regulating miR-107/ CDK6 pathway. J Exp Clin Cancer Res 35: 22, 2016.

96. Xue M, Chen W, Xiang A, Wang R, Chen H, Pan J, Pang H, An H, Wang X, Hou H and Li X: Hypoxic exosomes facilitate bladder tumor growth and development through transferring long non-coding RNA-UCA1. Mol Cancer 16: 143, 2017.
97. Juni RP, Abreu RC and da Costa Martins PA: Regulation of microvascularization in heart failure-an endothelial cell, non-coding RNAs and exosome liaison. Noncoding RNA Res 2: 45-55, 2017

98. Lu Z, Xiao Z, Liu F, Cui M, Li W, Yang Z, Li J, Ye L and Zhang $\mathrm{X}$ : Long non-coding RNA HULC promotes tumor angiogenesis in liver cancer by up-regulating sphingosine kinase 1 (SPHK1). Oncotarget 7: 241-254, 2016.

99. Tan J, Qiu K, Li M and Liang Y: Double-negative feedback loop between long non-coding RNA TUG1 and miR-145 promotes epithelial to mesenchymal transition and radioresistance in human bladder cancer cells. FEBS Lett 589: 3175-3181, 2015.

100. Qin CF and Zhao FL: Long non-coding RNA TUG1 can promote proliferation and migration of pancreatic cancer via EMT pathway. Eur Rev Med Pharmacol Sci 21: 2377-2384, 2017.

101. Li Z, Zhao L and Wang Q: Overexpression of long non-coding RNA HOTTIP increases chemoresistance of osteosarcoma cell by activating the Wnt/ $\beta$-catenin pathway. Am J Transl Res 8: 2385-2393, 2016.

102. Lang HL, Hu GW, Zhang B, Kuang W, Chen Y, Wu L and Xu GH: Glioma cells enhance angiogenesis and inhibit endothelial cell apoptosis through the release of exosomes that contain long non-coding RNA CCAT2. Oncol Rep 38: 785-798, 2017.

103. Liu T, Zhang X, Gao S, Jing F, Yang Y, Du L, Zheng G, Li P, Li $\mathrm{C}$ and Wang C: Exosomal long noncoding RNA CRNDE-h as a novel serum-based biomarker for diagnosis and prognosis of colorectal cancer. Oncotarget 7: 85551-85563, 2016.

104. Isin M, Uysaler E, Ozgur E, Koseoglu H, Sanli O, Yucel OB, Gezer U and Dalay N: Exosomal lncRNA-p21 levels may help to distinguish prostate cancer from benign disease. Front Genet 6: 168, 2015.

105. Wang Y, Liu XJ and Yao XD: Function of PCA3 in prostate tissue and clinical research progress on developing a PCA3 score. Chin J Cancer Res 26: 493-500, 2014.

106. Godinho M, Meijer D, Setyono-Han B, Dorssers LC and van Agthoven T: Characterization of BCAR4, a novel oncogene causing endocrine resistance in human breast cancer cells. J Cell Physiol 226: 1741-1749, 2011.

107. Jang SY, Kim G, Park SY, Lee YR, Kwon SH, Kim HS, Yoon JS, Lee JS, Kweon YO, Ha HT, et al: Clinical significance of lncRNA-ATB expression in human hepatocellular carcinoma. Oncotarget 8: 78588-78597, 2017.

108. Nie FQ, Sun M, Yang JS, Xie M, Xu TP, Xia R, Liu YW, Liu $\mathrm{XH}$, Zhang EB, Lu KH and Shu YQ: Long noncoding RNA ANRIL promotes non-small cell lung cancer cell proliferation and inhibits apoptosis by silencing KLF2 and P21 expression. Mol Cancer Ther 14: 268-277, 2015.

109. Pang Q, Ge J, Shao Y, Sun W, Song H, Xia T, Xiao B and Guo $\mathrm{J}$ : Increased expression of long intergenic non-coding RNA LINC00152 in gastric cancer and its clinical significance. Tumour Biol 35: 5441-5447, 2014

110. Xu N, Chen F, Wang F, Lu X, Wang X, Lv M and Lu C: Clinical significance of high expression of circulating serum lncRNA RP11-445H22.4 in breast cancer patients: A Chinese population-based study. Tumour Biol 36: 7659-7665, 2015.

This work is licensed under a Creative Commons Attribution-NonCommercial-NoDerivatives 4.0 International (CC BY-NC-ND 4.0) License. 